\title{
Key driven business reengineering - How to get reengineering more efficient and effective
}

\author{
M. Stamminger \\ Information systems production planning, Volkswagen $A G$ \\ Postbox 1832, D-38436 Wolfsburg, Germany \\ Tel.: $+49 / 5361-9-21646$, \\ Fax: $+49 / 5361-9-21136$, \\ e-mail:devw1bjk@ibmmail.com
}

\begin{abstract}
Hardly any management concept has been discussed as much as the reengineering of business processes and numerous articles using many of todays buzz words of business have been published. In spite of the wealth of information that is available many reengineering projects fail because the quantum leaps expected do not take place with conversion. The reasons for this are varied, but the common characteristic of failure is the lack of a systematic implementation approach.

This paper will present a methodical approach for the implementation of a key driven business reengineering program, which supports the planning, realization and controlling of reengineering measures. In this connection the role of an integral target system is described in order to identify the essential key factors and targets for an orientation of reengineering activities. Therefore, the choice of reengineering measures, whether the reengineering carried out should be evolutionary or radical, depends on the value added potential and the prioritization determined. Another aspect is the use of indicators as instruments for controlling in order to identify additionally needed reengineering measures. The result could be to reach new potentials and to get more benefits in reengineering, while decisions for investment in new resources, for example innovative information technology, will be more efficient and effective.
\end{abstract}

\section{Keywords}

Experiences and failures in reengineering, key driven business reengineering, business process reengineering, business process management, target system, key factor, indicator. 


\section{INTRODUCTION}

\section{1 "State of the art" and best practice in business reengineering}

Shorter product life cycles combined with the globalization of the competitive environment require a permanent effort to increase productivity and a reduction of product development time (Time to Market). For most companies the pressure is becoming more intense to be faster and cheaper. This leads to a conflict of objectives for most existing organizations. To achieve more competitive advantages, many companies have focused their optimization activities on net product potentials (Bullinger, 1995). For this reason, more and more companies are defining new visions and are looking for economies of scale in their most important business processes.

When looking at the dynamic change of management concepts over the last decades, the transformation process in the companies can be split into different phases. Above all, the change in point of view is characteristic. Figure 1 shows the transformation over the years from rationalization to continuous improvement (for example Lean Management, TQM, etc.) to the renewal phase, including the concepts business reengineering and Concurrent/ Simultaneous Engineering.

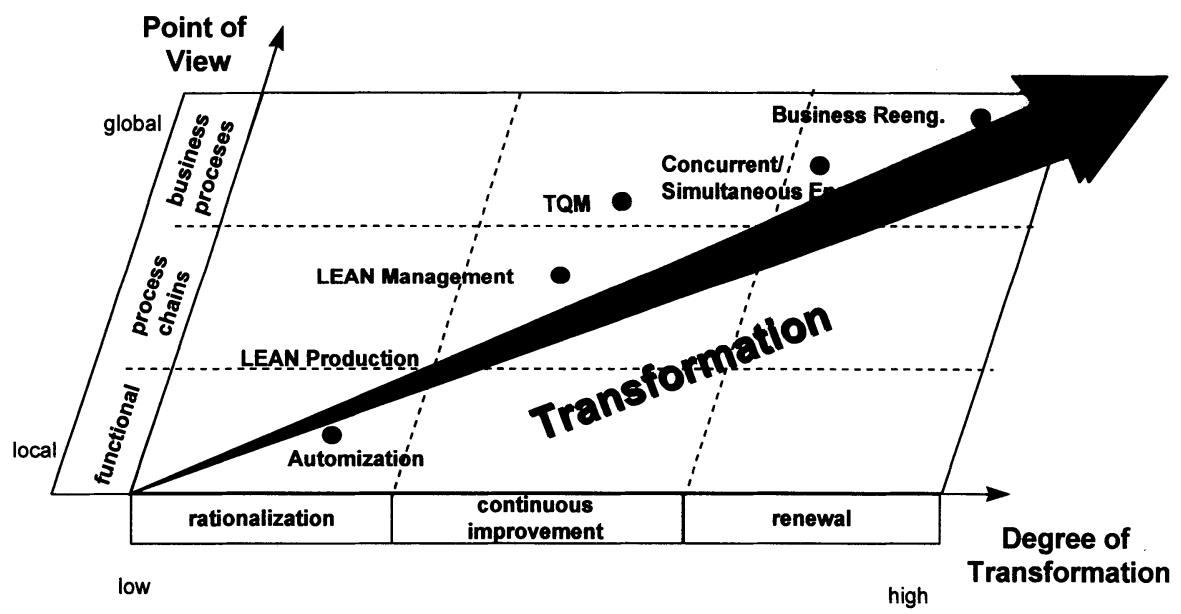

Figure 1 Dynamic change of management concepts (acc. to Bullinger, 1995).

While functional aspects were at the forefront of analysis and optimization in the past, emphasis has now shifted to a global view of business processes. Business processes are defined as processes, which have a strong influence on the fulfillment of customer requirements. In other words: "Everything the customer does not appreciate is a waste!"(Hammer, 1995). Therefore, the main objective is to achieve drastic improvements in business performance, which can be measured directly in the market. In this connection for a couple of years, the slogan reengineering draws attention. Hardly any management concept has been discussed in publications in the past as much as the term of business reengineering. Numerous concepts 
with all sorts of term variations have been developed while companies are still looking in vain for the right approach, for solutions to all their problems (Homburg, 1996).

At the beginning of the 90 's the economic crisis demonstrated that companies were not reaching the potential of change, necessary to achieve the stronger demands of the market (Bullinger, 1995). However, from practical experience, it can be determined that many reengineering projects fail or do not achieve the high level of success expected (Scott, 1994 and CSC-Index, 1994). A study in a hundred German companies showed that business reengineering has failed with its approach and that there is a general imbalance between expectation and reality (Homburg, 1996). Therefore, nearly all interviewed companies hoped for increased productivity, but only a quarter of them reached this goal. The essential reasons for failures can be described and categorized as following:

\section{Human aspects}

Hammer and Champy claim that many reengineering projects are threatened to fail because the management maintains classic leadership and organizational structures and do not rethink these fundamental principles (Womack, 1996). Studies in the USA illustrated that there is a causal relationship between the motivation of management and the achievement of the targets (Hall, 1993). Failure occurs, therefore, because the theory of a global view of business process is not thoroughly implemented. Functional barriers are still hindering the search for solutions linking all areas.

Another aspect causing failure is that persons affected within the processes are not sufficiently integrated into the reengineering activities. Thus many employees are unwilling to adopt this approach. They are uncertain and afraid about their job security due to the employee reductions made over the last decades. The identification and motivation for a common vision are lost by many employees. In this context Scott-Morgan (1994) argues that drastic measures with aggressive targets could not be enforced in most companies.

Further, in complex problems as we can identify them, the persons affected tend to disregard essential factors outside of their own organizations. This creates the risk that problems resulting from reengineering will not be observed and corrected because of this isolated view. The problems in the companies often are not focused through different perspectives, so they are not recognized sufficiently by the employees. The reason for this is that they are overloaded with daily problems and are not using their knowledge and experience to manage the situation (Dörner, 1989).

\section{Missing target orientation}

Very often the knowledge for completing a reengineering project is lacking. This hides the danger that in the analysis phase, i.e. the modeling of the actual state artificially complicated. is overtly extended thus pushing the real goal of the reengineering the definition and implementation of concrete solutions into the background. From practical experience it can be determined that often a poor systematic approach is found in the companies. Additionally a clear target orientation is not present. Furthermore, a continuous instrument for measurement and controlling of reengineering activities such as process analysis or definition, etc. do not exist. Thus it is almost impossible to check the efficiency of reengineering measures in order to minimize the risk of failure (Stamminger, 1996). 
In practice concrete targets which are used as a basis for assumption in order to work out the right priorities for a target-oriented reengineering are often lacking. Quantum leaps expected do not take place because targets were set too low and market-oriented success parameters were neglected (CSC-Index, 1994). Often, however, the success parameters are not known which are necessary to achieve a breakthrough (Bullinger, 1995). In the search for these parameters or essential key factors for reengineering, the complexity of problems in the companies are often estimated incorrectly. The analysis of different perspectives and influencing factors between the processes is normally not taken into account. With regards to the global or local aspects in business processes, the possible benefits of reengineering measures could not be estimated through a single (one-sided) approach (Gomez, 1995). This hides the risk of sub-optimization, which means that the whole performance of the company could be disturbed. For example, when reengineering cost or profit centers, this becomes recognizable because competing targets can often be found which may negatively influence the strategic targets of the company. Besides, the mistake of structuring targets in form of hiercharchical structures is still being made. This may be a main reason why contributing to erroneous conclusions regarding the prioritization of reengineering measures (Stamminger, 1996).

\section{Problems in process modeling}

process modeling is a creative and complex task. The main objective is to model information about a defined part of the system which is to be considered. To achieve this, systematic methods and modeling techniques are required. In this respect, a whole range of modeling techniques (ARIS, IEM, CIMOSA, etc.) and computer assisted tools (ARIS, MOOGO, etc.) are now available to deal with the problems involved. However, from practical experience, it is often not clear whether and on which level the affected processes shall be modeled to get evident facts about organizational weak points, etc.. Predominantly process models are being used for visualization and as a basis to discuss possible solutions through the team involved in the reengineering process, which the author will not criticize here. It should rather emphasize the danger that with only illustrating the actual state through, for example modeling information flows as well as marking weak points, etc. the reengineering work has not been completed. A continuous conversion of reengineering projects from analysis to the process definition often is not guaranteed and goes too lazy.

\subsection{Objective of this paper}

As discussed above it becomes obvious how many different aspects must be considered, to make business reengineering successful. Above all, the human resources must be better integrated in the cycle of reengineering. Consequently, there is an urgent call to action to set in motion changes in mind sets necessary to develop and implement common visions. In our companies this can only be achieved through a responsible action and personal conviction (Gomez, 1995 and Cooper, 1994).

Summarizing this, besides the human aspects the author sees the main potential in the procedure of reengineering to increase efficiency and effectiveness. In order to minimize the risks of failure in reengineering projects it is important to solve the problems in a company's organization in a systematic way. The following thesis will help to develop such a procedure: 
- The approach must support a cross-functional point of view through the organizational divisions affected at any reengineering phase.

- The reengineering must always be target-oriented.

- The results of reengineering activities have to be measurable in any phase and the procedure must obtain several evaluation steps in order to set new priorities for additional reengineering measures.

- The cycle of business reengineering must support the results from the phases of process analysis to definition continuously.

- Alterations and sources of disturbance must, as a result of the procedure, be able to be verified and updated frequently as the the need arises.

\section{KEY DRIVEN BUSINESS REENGINEERING}

As discussed in the previous chapter there are many reasons why reengineering fails. To achieve more success a systematic approach is required. This article presents a methodical approach for a continuous planning, realization and controlling of reengineering activities. A target system forms the central core of this approach, which controls the reengineering through key factors and concrete targets. Furthermore, the procedure supports the controlling of reengineering activities and the definition of additional measures if necessary. The result is to carry out new potentials and to get more benefits from reengineering, while analysis, definition and implementation of the process itself is more efficient and effective.

On the basis of the thesis listed above, the global cycle of business reengineering is introduced in a first step. As shown in figure 2 the cycle is subdivided in two areas Business Process Reengineering and Business Process Management. While process reengineering includes all activities which have to do with the modeling of business processes, process Management is understood as controlling the processes on the operative level in a company. This means that process Management takes on the function of an early warning system, in order to obtain information about actual events or trends for future anticipation (Krystek, 1993).

As mentioned above the target system plays a significant role in the cycle of business reengineering and serves for orientation and controlling of reengineering measures. Through its results, the target system forms the base to determine whether and where reengineering measures are necessary. Furthermore, it determines whether the reengineering carried out should be evolutionary or radical. Therefore it supports the various phases of business reengineering from:

- process analysis,

- process definition via

- implementation to

- continuous improvement entirely.

It is characteristic for the circle displayed in figure 3 that the several phases cannot be seen purely as a sequential series of activities which are passed through uniquely, but also as a networking problem solution process with iterating action steps. The results within the phases can be evaluated by a constant comparison of the actual state with the target set. This allows 
for interaction at anytime in the reengineering process with additional measures if the deviation is determined to be too large. Through the continuous interaction of the target system the cycle of business reengineering is considerably more insensitive to changes of basic conditions or new impulses. Therefore, the danger of the whole project failing can be minimized.

To achieve more potential and efficiency in reengineering the essential success factors have to be found in the company's organization. Another important aspect is to transform these key factors into concrete targets. The definition of targets for a company is the basic precondition to identify facts as problems and to assess the effectiveness of solutions (Scholz, 1993). As shown in the previous chapter, in practice many deficits occur while specifying key factors and targets needed for a key driven reengineering.

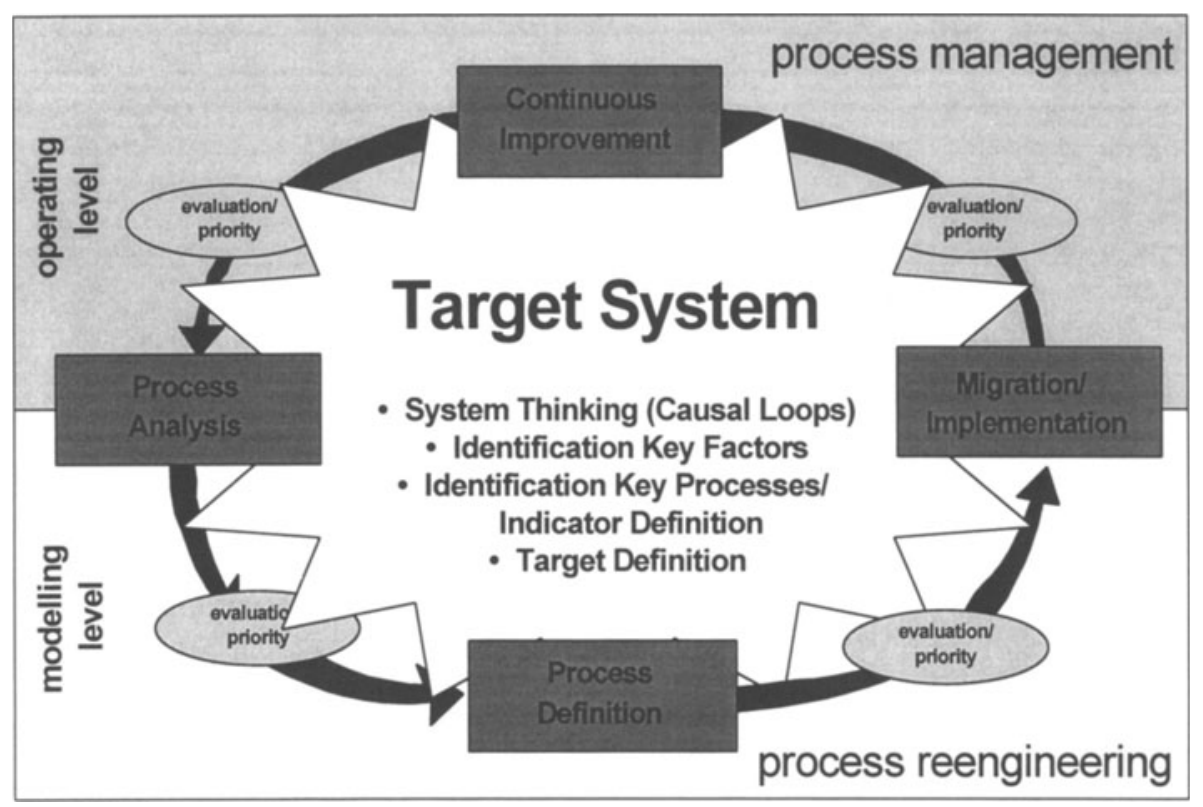

Figure 2 The complete cycle of business reengineering (Stamminger, 1996).

The following questions have to implement successful reengineering:

- How can the essential key factors be identified?

- Which processes shall be improved and which organizational units are affected?

- What effects on other processes can be expected through reengineering?

- What benefits are available and how high should the targets be set?

- Which indicators are needed to assess the performance of the processes and the quality of their outcomes?

- How can the results of reengineering measures be controlled? 
The cycle of business reengineering starts by recognition of needed reengineering measures. This can be initiated through a culture change in the company, for example from a purely functional thinking to a process orientation. Another impulse initiating change can occur, if the indicators in process controlling determine that the performance goes out of tolerance drastically. In such cases measures within the phase of continuous improvement are not sufficient to solve these problems, thus the conditions in the company have to be checked. This is guaranteed through the several steps in the target (system) definition process as shown in figure 3 .

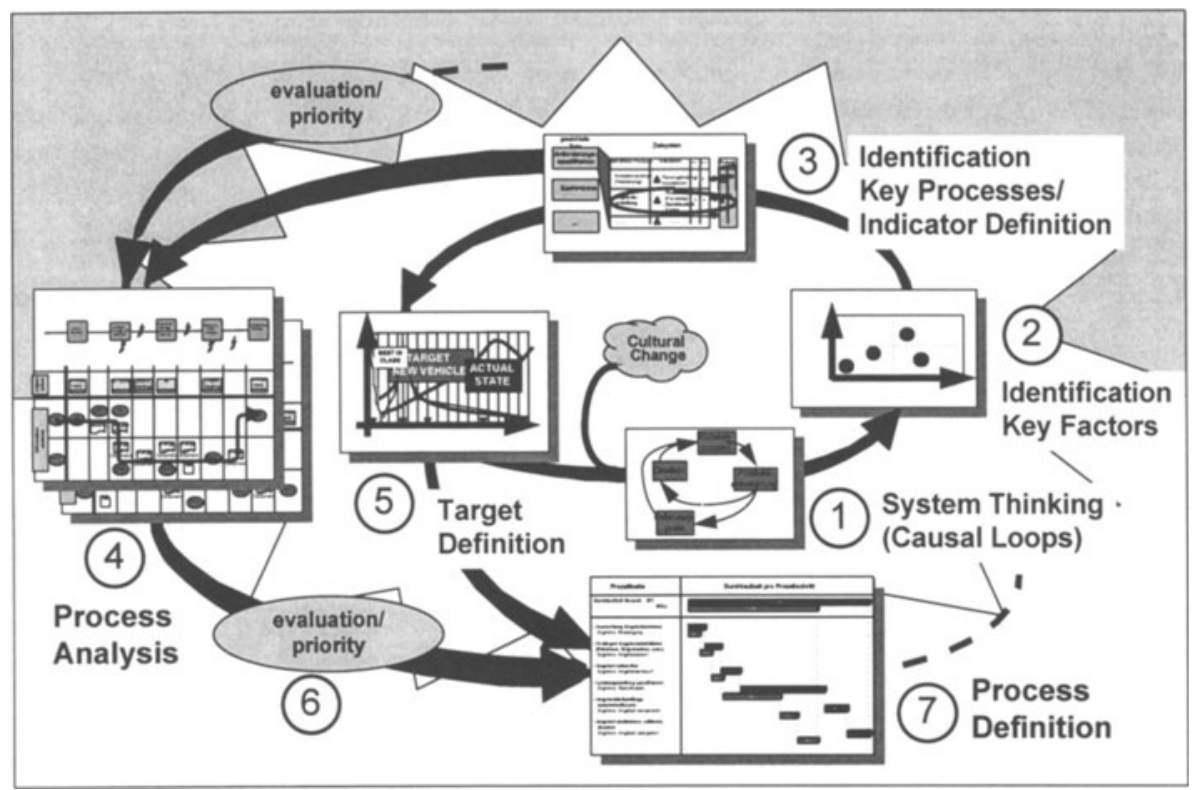

Figure 3 Example for interaction between target system and business process reengineering.

For a better comprehension of the interaction between the target system and the respective phases of business reengineering the several steps of the procedure are described in more detail as follows:

\section{System Thinking (1)}

Today many companies are characterized through complex processes and structures in their organization. Additionally they actually occur with many combinations and are influenced or disturbed dynamically through many factors. These kind of systems are called complex systems, which have the property that they cannot be determined exactly (Gomez, 1995). A good example for a such complex situation is the change of the markets from a vendor to a customer-oriented market. The fact is that the companies are now no longer independent and isolated from the developments beyond their environment (Krystek, 1993). 
From practical experience it can be determined that the analysis of complex systems is a difficult task because we tend to neglect important aspects while searching for solutions quickly without reaching an integral position of the problem and aspects belonging to it (Gomez, 1995). One example of this is the structuring of success factors in the form of target hierarchies. Often targets are developed from strategic aims of management through a topdown approach. This hides the danger that real relations of cause and effect of complex situations, especially of business processes, will not be sufficiently realized.

The method of "System Thinking" supports the analysis of the most important influences and relations in complex situations. Furthermore, it is possible to visualize these aspects and to check the intense and dynamic influence of the system components (Gomez, 1995). To achieve this relevant aspects of process actions should be considered from different perspectives within the company. As a consequence, it is necessary to determine suitable and essential key factors, which allow a balance between global and local relations in the company. Afterwards, these key factors including their relationships to one another can be visualized with cause and effect diagrams.

\section{Interpretation (2)}

After the presentation of the key factors in the cause and effect diagrams it is necessary to analyze the relationships through a qualitative and the quantitative valuation process. To achieve the correct success parameters, and thus priorities for reengineering measures, the intensity of the relations among the key factors has to be analyzed. Depending on the influence to and from other factors an active and passive value can be evaluated and presented in a special diagram. This distinction is of considerable interest, because the separate values are then classified so that the critical factors can be identified to establish priorities for a key driven reengineering. It is obvious that it makes only little sense to concentrate the activities on factors which have only low influences on others, or where an interference itself is very difficult. To summarize this, key factors are defined as parameters which have a large influence on others. These are most suitable for the introduction of reengineering measures because they possess a high potential for improvement and build on the assumption for successful business reengineering.

\section{Identification of key processes (3)}

If the key factors and the priorities for reengineering measures were specified it is obvious that for each key factor the processes affected have to be identified. This simply means which processes in the company have a major influence on the key factors through their outputs and process performance. For example, if the "start of production" was identified as a critical factor, the subprocesses of purchasing of manufacturing equipment and/or engineering change management could be affected. Another aspect to be taken into consideration is the definition of suitable indicators. Indicators make measurements possible so they are used as controlling instrument because they help to register deviations from the targets set (Fries, 1994).

\section{Process analysis (4)}

In a next step, depending on the results of the determined success parameters, specific aspects of the processes and organizational units affected can be analyzed in more detail with the 
methods of process modeling. Concerning the analysis of processes, the flow of information is at the center of observations. At this point it is interesting, which information is exchanged when and how, in which form and how often, by whom and for whom it is prepared etc.. Furthermore, it is required to model the information flow in an entire and logical context. To achieve more transparency in process action and to get more information with regard to weak points it is necessary to measure the performance of the processes on the basis of the defined indicators. This means that all input and output relations regarding cost, duration (including the quality of outputs) have to be evaluated. This is the basis for a better estimation of reengineering potentials and target definition.

\section{Target definition (5)}

To get an orientation for reengineering it is important to check the results of the process analysis against improvement potentials in order to set priorities. Based on the established potentials and actual performance of the processes affected, in the next step targets must be concretely defined. Therefore, the choice of reengineering measures, whether the reengineering carried out should be evolutionary or radical, depends on the value added potential and the prioritization set through the targets determined. The ability of quantifying the targets makes it possible to exactly measure and evaluate the imortant facts. The targets are specified through a value or defined value range. To better utilize the target definition process the bench marking concept is helpful. It has been introduced successfully in the past and allows the comparison of facts between other companies, especially competitors. Thus it is possible to recognize trends or changes earlier.

\section{Evaluation (6)}

As described already, the cycle of business reengineering is characterized through several evaluation steps after each phase. Thus the iteration within the procedure is supported by the results of reengineering activities itself. For example, the progress within the phase of process analysis can be checked continuously if the specified processes were analyzed completely. This is important if the conditions in the reengineering project change so that new requirements and aims from the target system can occur. For example, regarding additional activities in process analysis. Therefore it is necessary to be able to interfere at any time of reengineering in order to set new priorities. The continuous interaction of the target system with the respective reengineering measures has the effect that the procedure is more insensitive to interference and/or new impulses from outside. Thus the evaluation steps make it possible to minimize failures and maximize the contributions of sources for a success reengineering sources.

\section{CONCLUSION}

To sum up one can see that business reengineering can be controlled through a systematic and key driven approach. A further characteristic of this approach is the integration of Business Process Reengineering and Business Process Management. Through the cycle of business reengineering results of the several phases can be evaluated at any time. Thus decisions 
concerning analysis and definition are oriented entirely to essential key factors. The choice of reengineering measures, i.e. whether the reengineering carried out should be evolutionary or radical, depends on the value added potential and the prioritization determined through the targets. In process performance measurements, indicators play an important role in order to make efficiency and effectiveness of business processes more transparent and serve for a better conduit of information for all those involved in the processes.

\section{REFERENCES}

Bullinger, H.-J., Wiedmann, G., Niemeier, J., (1995), "business reengineering- IAO-Studie 1995", Institut für Arbeitswirtschaft und Organisation, Stuttgart, pp.7-31.

Cooper, R., Lynne, M., (1996), "Human reengineering", in Harvard business Manager 1/1996, Sloan Management Review Association, pp. 77-89.

Dörner, D., (1989), "Die Logik des Mißlingens", Rowohlt-Verlag, Reinbek.

CSC-Index, (1994), "State of reengineering Report, Executive Summary.

Fries, S., Seghezzin, H.-D., (1994), "Entwicklung von Meßgrößen für Geschäftsprozesse", in Controlling Nr.6, pp. 338-345.

Gomez, P., Probst, G., (1995), "Die Praxis des ganzheitlichen Problemlösens: Vernetzt denken, unternehmerisch handeln, persönlich überzeugen", Haupt-Verlag, Bern/Stuttgart.

Hammer, M., (1990), "Re-engineering Work: Don't Automate, Obliterate", Harvard business Review, July/Aug., pp. 104-112.

Hammer, M., Champy, J., (1995), "business reengineering- Die Radikalkur für das Unternehmen, Vol.5, Campus-Verlag, Frankfurt/New York.

Hall, G., Rosenthal, J., Wade, J., (1994), "How to make reengineering really work, in Harvard business Review Nr.6, pp. 119-131.

Homburg, C., (1996), "Traurige Bilanz", Manager magazine 8/96, pp 112-113.

Krystek, U., Müller-Stewens, G., (1993), "Frühaufklärung für Unternehmen: Identifikation und Handhabung", Schäffer-Poeschel, Stuttgart.

Scholz, R., (1993), "Geschäftsprozessoptimierung: crossfunktionale Rationalisierung oder strukturelle Reorganisation, Dissertation Univ. der Bundeswehr, Hamburg, pp. 115-140.

Scott-Morgan, P., (1994, "Die heimlichen Spielregeln. Die Macht der ungeschriebenen Gesetze im Unternehmen", Frankfurt.

Womack, J., (1996), "News from Hammer and Champy", in Harvard business Manager 1/1996, Sloan Management Review Association, pp.15-17.

\section{BIOGRAPHY}

Dipl.-Ing. Markus Stamminger, born in 1966, studied mechanical engineering at the Technical University in Karlsruhe, Germany. Main subjects were production engineering and integrated CAD/CAM-solutions. He joined the Volkswagen Group in Wolfsburg in 1994. In the project IMPULS he is involved in reengineering the process of production preparation for new vehicles. Based on his practical experiences he writes his dissertation about systematic approaches for business reengineering in the automotive industry. 